\title{
Mudanças percebidas por familiares de crianças/adolescentes em sofrimento mental que participam de grupos operativos
}

Changes perceived by family members of children/adolescents experiencing psychic suffering who participated in an operational group

Cambios percibidos por familiares de niños/adolescentes bajo padecimiento mental que participan de grupos operativos

Maria Cícera dos Santos Albuquerque ${ }^{1}$, Yanna Cristina Moraes Lira Nascimento ${ }^{2}$, Mércia Zeviani Brêda ${ }^{3}$, Luana Cecylia Gomes Luca ${ }^{4}$

\footnotetext{
${ }^{1}$ Enfermeira, Doutora em Enfermagem Fundamental. Professora Associada da Universidade Federal de Alagoas (UFAL). Maceió, AL, Brasil. E-mail: cicera.albuquerque@hotmail.com.

${ }^{2}$ Enfermeira, Mestre em Enfermagem. Professora Auxiliar da UFAL. Maceió, AL, Brasil. E-mail: yanna cristina@hotmail.com.

${ }^{3}$ Enfermeira, Doutora em Enfermagem Psiquiátrica. Professora Adjunto da UFAL. Maceió, AL, Brasil. E-mail: merciazb@gmail.com.

${ }^{4}$ Discente do curso de Graduação em Enfermagem da UFAL. Maceió, AL, Brasil. E-mail: luana_cecylia@hotmail.com.
}

\section{RESUMO}

Estudo exploratório-descritivo, de natureza qualitativa que objetivou identificar mudanças percebidas por familiares de crianças e adolescentes em sofrimento mental que participam de grupos operativos. Os dados foram coletados por meio de entrevistas semiestruturadas com oito familiares de crianças e adolescentes e submetidos a análise temática, gerando três categorias: a) mudanças na expressão de sentimentos, b) mudanças na percepção de si e c) aprendizagem de técnicas para lidar com o sofrimento mental. Os resultados evidenciaram que os grupos oportunizam alívio de tensões, funcionam como espaço de esclarecimento e escuta, ajudam no compartilhamento das inquietações, melhoram a convivência familiar, estimulam o cuidado de si, ensinam a utilizar técnicas de manejo de convivência. Conclui-se que os benefícios percebidos pelos familiares que participam dos grupos reforçam que é possível facilitar grupos operativos baseados na teoria pichoniana. Para tanto, a compreensão, apreensão e manejo do uso desta tecnologia depende de formação qualificada do profissional enfermeiro.

Descritores: Cuidados de Enfermagem; Saúde da Criança; Adolescente; Família; Estresse Psicológico.

\section{ABSTRACT}

An exploratory descriptive study of qualitative approach with the objective to identify the changes perceived by family members of children and adolescents in psychic suffering who participated in operational groups. The data were collected using semi-structured interviews conducted with eight family members and then submitted to thematic analysis, generating three categories: a) change in emotional expression, b) change in self-perception and c) learning techniques for dealing with psychic suffering. The results demonstrated that the groups provide an opportunity for tension relief, function as spaces for clarification and listening and sharing concerns, improve family interactions, stimulate self-care, and teach members how to use social interaction techniques. We conclude that the benefits perceived by family members participating in groups demonstrate the possibility of facilitating operational groups based on Pichon Rivière's theory. To this effect, nursing professionals must receive qualified training in order to comprehend, apprehend and make use of this technology.

Descriptors: Nursing Care; Child Health; Adolescent; Family; Stress, Psychological.

\section{RESUMEN}

Estudio exploratorio-descriptivo, de naturaleza cualitativa, objetivando identificar cambios percibidos por familiares de niños y adolescentes bajo padecimiento mental que participaron de grupos operativos. Datos recolectados mediante entrevistas semiestructuradas con ocho familias de niños y adolescentes, sometidos a análisis temático, generándose tres categorías: a) cambios en la expresión de sentimientos, b) cambios en la propia percepción y c) aprendizaje de técnicas para enfrentar el padecimiento mental. Los resultados evidenciaron que los grupos ofrecen alivio de tensiones, funcionan como espacio de esclarecimiento y escucha, ayudan a compartir inquietudes, mejoran la convivencia familiar, estimulan el cuidado propio, enseñan a utilizar técnicas de manejo de la convivencia. Se concluye en que los beneficios percibidos por los familiares que participaron de grupos refuerzan la posibilidad de establecer grupos operativos basados en la teoría pichoniana. Para ello, la comprensión, aprendizaje y manejo del uso de esta tecnología depende de la formación calificada del profesional de enfermería.

Descriptores: Atención de Enfermería; Salud del Niño; Adolescente; Familia; Estrés Psicológico. 


\section{INTRODUÇÃO}

A família em suas múltiplas formas, por ser o primeiro grupo social de interação responsável por proteger e promover a socialização da criança é quem primeiro interfere no comportamento para a formação da personalidade ${ }^{(1)}$.

Entretanto, nem sempre a família é fator de proteção para seus membros, principalmente quando a criança é acometida por um transtorno mental e toda a dinâmica familiar passa a ser alterada. Nesta condição, é preciso adaptar-se à nova realidade. A família precisa desenvolver habilidades, a fim de compreendê-los, ajudá-los e inseri-los na sociedade. Para isso, suporte emocional, orientações e cuidados são necessários ${ }^{(2-4)}$.

$\mathrm{Na}$ rede de serviços para o atendimento da saúde mental da criança e do adolescente, o Centro de Atenção Psicossocial Infanto-Juvenil (CAPSi) pode propiciar este suporte. Neste serviço de saúde de média complexidade, de base comunitária, referência para crianças e adolescentes que apresentam transtornos mentais severos em um município, a família passa a ser considerada sua maior aliada no cuidado, acompanhando o processo de reabilitação psicossocial de suas crianças e adolescentes, e participando de grupos operativos com finalidade terapêutica. Neste serviço investe-se no aprimoramento do comportamento humano, por meio de intervenções diretas às crianças e adolescente, bem como a suas famílias. Por isso, torna-se indispensável a ação dos profissionais da saúde para com este grupo social, a família ${ }^{(5-7)}$.

Atividades grupais a familiares tem sido muito utilizadas por profissionais nos serviços de saúde, e em especial nos CAPSis. Principalmente, por esta atividade constituir-se em ferramenta potencializadora de um trabalho produtivo quando desenvolvida em ambientes saudáveis e democráticos que estimulam a arte da convivência ${ }^{(8)}$.

A intervenção grupal em familiares, entre outros benefícios, melhora a comunicação na família, atenua conflitos com maior eficácia e aumenta a competência e habilidade dos pais em lidarem com a doença ${ }^{(9)}$. No entanto, o domínio do manejo de grupo deve ser sustentado por um referencial teórico-prático que na maioria das vezes os profissionais não o conhecem ${ }^{(8)}$.

A falta do conhecimento adequado muitas vezes levam os profissionais a desenvolverem atividades grupais de forma empírica ou com base no senso comum, sem planejamento, correndo o risco de desagregar, e não mobilizar estruturas internas do comportamento, mas, quando estas atividades passam a Rev. Eletr. Enf. [Internet]. 2014 jul/set;16(3):652-61. Disponível em: http://dx.doi.org/10.5216/ree.v16i3.21777. - doi: 10.5216/ree.v16i3.21777. ser desenvolvidas sob um olhar de uma teoria os resultados tornam-se mais satisfatórios, e a facilitação do grupo se torna mais tranquila( ${ }^{(8,10-13)}$.

Neste sentido, o olhar de Pichon-Rivière para a família como a primeira estrutura grupal do qual uma pessoa participa, tem defendido uma abordagem terapêutica a partir de grupos operativos. Este tipo de abordagem pode sensibilizar cada sujeito em sua singularidade, e provocar interessantes transformações em suas relações cotidianas, consigo mesmo, com os outros, com o mundo, conferindo-lhes movimento e aprofundamento, provocando um novo lugar, lugar de potência, de realização, de saber, de inclusão, para as populações geralmente marcadas pela falta, pelo não saber, pela exclusão e pressões advindas da sociedade no qual está inserida(11,13).

A finalidade e o propósito dos grupos operativos está centrado na mobilização de estruturas estereotipadas, nas dificuldades de aprendizagem e comunicação que acabam por despertar ansiedade. Ansiedade esta gerada pelo medo do abandono ao vínculo anterior como pela insegurança da formação de um novo vínculo(10-11).

Desta forma o grupo passa a ter uma tarefa externa, delimitada por objetivos conscientes, e uma tarefa interna, relações geradas no próprio grupo a fim de realizar o seu trabalho ${ }^{(14)}$.

O uso do grupo operativo baseado na técnica pichoniana, mesmo que de "forma adaptada", tem sido uma prática ainda pouco incorporada pelos CAPSis, mas, que tem apresentado resultados favoráveis às relações entre cuidadores e, suas crianças e adolescentes em sofrimento mental ${ }^{(13)}$. A adaptação da técnica pichoniana no contexto dos serviços de saúde é bastante comum, até porque o próprio Pichon Rivière defendia que muitos dos princípios de sua teoria podem ser utilizados em grupos terapêuticos conduzidos por profissionais da saúde que não necessariamente são psicoterapeutas ${ }^{(11)}$.

Estudo $^{(13)}$ aponta que atualmente, nas áreas de atuação do psicólogo, do assistente social, do enfermeiro e de outros profissionais que coordenam grupos, há crescente utilização do termo grupo operativo para se contrapor ao grupo psicoterapêutico. Entretanto, não se trata do grupo operativo classicamente baseado na teoria pichoniana, mas de grupos de aprendizagem, que também podem ser terapêuticos, quando levam ao alívio de sintomas, o desenvolvimento de comportamentos mais saudáveis e o autoconhecimento, se esses forem o objetivo ou a tarefa do grupo ${ }^{(13)}$.

Quando o campo operativo do grupo passa a ser terapêutico, a tarefa é resolver o denominador comum 
da ansiedade do grupo adquirida pelas características particulares de cada membro. No caso da família, os diversos papéis que podem ser trabalhados no contexto grupal, permitem que o coordenador ajude no alivio de tensões ${ }^{(11)}$. Por essa razão os grupos que tem influencia dessa abordagem teórico metodológica tem obtido bons resultados nos serviços de saúde, em particular, no atendimento de famílias de crianças e adolescentes em adoecimento mental ${ }^{(15)}$.

Assim, essa ferramenta ajuda a família na mudança de condutas e comportamentos que sejam mais adequados ao convívio social. Esses são comuns durante os atendimentos grupais nos CAPSis. Quem participa de grupo operativo é estimulado diariamente ao autocuidado, favorecendo maior adesão ao tratamento, reforçando o vínculo à unidade de saúde a partir da articulação entre os participantes do grupo que possuem motivações em comum ${ }^{(16)}$.

Nos grupos operativos ocorrem o compartilhamento de experiências, integração de saberes e afetos favoráveis ao amadurecimento, descobertas de novas formas de convívio, para que a família cumpra suas tarefas básicas de: prestação de cuidados, nutrição dos sentimentos de pertença e coesão a um grupo, permissão para a individuação, autonomia e socialização dos seus membros ${ }^{(13)}$.

O grupo operativo junto à família oferece suporte para lidar com a criança e adolescente em adoecimento mental, como também ressignificar a experiência de ser familiar cuidador ${ }^{(15,17)}$. Além disso, os grupos operativos propiciam uma capacidade de pensar nas experiências emocionais cotidianas e aprender com elas; no grupo, o sujeito faz inúmeras introjeções de como os outros lidam com os problemas (catarse grupal).

Neste sentido, estudo tem reforçado quão relevante é incorporar definitivamente a prática de grupos operativos à familiares de crianças e adolescentes com transtornos mentais em serviços de saúde ${ }^{(10)}$. O domínio desta prática é imprescindível para o enfermeiro compreender os movimentos grupais, e desta forma suscitar mudanças de comportamento nos participantes da interação grupal ${ }^{(18)}$.

A identificação destas mudanças, apontando quais benefícios para os familiares que participam de grupos operativos, tem sido um dos motivos para o desenvolvimento desta pesquisa. Além deste, outros motivos foram: a necessidade de reforçar que mudanças de comportamento são melhores percebidas quando técnicas grupais baseadas em pressupostos teóricos são acessadas, e que a partir de sua utilização reflexos no Rev. Eletr. Enf. [Internet]. 2014 jul/set;16(3):652-61. Disponível em: http://dx.doi.org/10.5216/ree.v16i3.21777. - doi: 10.5216/ree.v16i3.21777. comportamento de suas crianças ou adolescentes são sentidas.

Diante do exposto, este artigo buscou identificar mudanças percebidas por familiares de crianças e adolescentes em sofrimento mental que participam de grupos operativos.

\section{MÉTODOS}

Pesquisa qualitativa de caráter descritivo exploratório, que além de observar, descrever e classificar a incidência do fenômeno busca explorar as dimensões deste, a maneira pela qual se manifesta e se relaciona ${ }^{(19)}$.

Os sujeitos da pesquisa foram familiares maiores de 18 anos, cuidadores de crianças e adolescentes em adoecimento mental acompanhados pelo CAPSi de uma capital do Nordeste do Brasil.

A seleção dos participantes ocorreu a partir da identificação dos mesmos nos livros de registro dos grupos operativos no período de 2009 a 2012 do referido serviço. Foram identificados e contatados quatorze familiares, abordados considerando-se os cuidados éticos para o desenvolvimento de pesquisa com seres humanos, atendendo as normas legais.

Foram incluídos no estudo familiares que tivessem frequentado ao menos um grupo operativo direcionado a família realizado por professores de saúde mental capacitados em dinâmicas de grupo que trabalham com a abordagem pichoniana e estudantes de enfermagem sob supervisão, ambos da Universidade Federal de Alagoas. Como critérios de exclusão definiu-se todos os nomes de participantes dos grupos operativos que não fosse possível contato telefônico.

$\mathrm{Na}$ abordagem inicial dos participantes foi mencionado o objetivo do estudo e garantido o anonimato das informações, momento em que oito sujeitos assinaram o Termo de Consentimento Livre Esclarecido. O estudo foi aprovado pelo Comitê de Ética em Pesquisa com Seres Humanos sob parecer de $n^{\circ}$ 021669/2011-47.

Os grupos basearam-se na teoria pichoniana de forma "adaptada" com o intuito de mobilizar estruturas internas a fim de estimular o compartilhamento de comportamentos mais adequados nos familiares, que colaborassem ainda mais com a diminuição das tensões e com o melhoramento da saúde de seus filhos.

Os grupos operativos para familiares aconteciam uma vez por semana em sala climatizada do CAPSi. Tinham duração de 90 minutos, eram grupos abertos com objetivos terapêuticos compostos geralmente por 12 
familiares. O planejamento era flexível ao interesse e necessidade dos membros do grupo, partindo do período de pré-tarefa, seguindo para a tarefa propriamente dita em que se trabalhavam comportamentos construindo-se também, em alguns encontros, objetos concretos (tarefa interna e externa). O último período da cada encontro culminava com a avaliação do momento vivenciado.

A coleta de dados ocorreu no período de fevereiro a abril de 2012, por meio de entrevistas individuais, semiestruturadas, com auxílio de um roteiro que explorava como foi participar dos grupos? Como se sentiam após os grupos? Se percebeu alguma diferença no seu jeito de ser após ter participado destes grupos? Se mudou a relação com o familiar em sofrimento mental após participação nos grupos? Se a participação no grupo o aproximou de seus familiares? Se houve alguma vez identificação do conteúdo abordado a partir da fala do outro participante do grupo?

As entrevistas foram previamente agendadas, gravadas, transcritas literalmente, e categorizadas com base na análise temática referenciada por $\operatorname{Bardin}^{(20)}$.

Deste modo, a análise desmembrou-se da seguinte forma: primeiramente transcreveu-se 0 material produzido, reformulando-o a partir de uma leitura flutuante; em seguida codificou-se o material a partir da identificação dos núcleos de sentido, transformando os dados brutos em dados compreensíveis no texto; depois realizou-se 0 tratamento dos resultados obtidos organizando os dados em um quadro com os possíveis temas que emergiram das falas, os recortes dos temas foram agrupados por similaridade, o que permitiu a identificação de três categorias temáticas: a)mudanças na expressão de sentimentos; b)mudanças na percepção de si e c)aprendizagem de técnicas para lidar com o sofrimento mental.

Na última etapa as categorias foram discutidas com base no referencial teórico de Pichon-Rivière ${ }^{(11)}$. Todas as categorias encontradas trazem relação com o processo grupal na perspectiva pichoniana quando evidenciam a forte mobilização de estruturas internas de personalidade dos familiares, reforçando a questão da tarefa como a aprendizagem necessária.

\section{RESULTADOS E DISCUSSÃO}

Para os participantes, após os grupos, houve mudanças na maneira de pensar, e de comportar-se frente as suas crianças e adolescentes, reforçando o alcance do propósito levantado por Pichon em relação a mobilização de estruturas estereotipadas, e da dificuldade de aprendizagem e comunicação.

Participaram do estudo cinco mães, um pai, um avô e uma avó segundo a descrição no Quadro 1.

Quadro 1: Caracterização dos cuidadores entrevistados. Maceió, AL, Brasil, 2012.

\begin{tabular}{|c|r|}
\hline & Caracterização dos sujeitos \\
\hline E1 & $\begin{array}{r}\text { Pai de um adolescente que frequenta o CAPSi a mais de um ano. Tem 41 anos, ensino fundamental } \\
\text { incompleto, é aposentado, e vem participando dos grupos há aproximadamente um ano. }\end{array}$ \\
\hline E2 & $\begin{array}{r}\text { Mãe de uma criança que frequenta o CAPSi a mais de um ano. Tem 31 anos, ensino fundamental } \\
\text { incompleto, é do lar, e vem participando dos grupos há aproximadamente cinco anos. }\end{array}$ \\
\hline E3 & $\begin{array}{r}\text { Avô de uma criança que frequenta o CAPSi a mais de dois anos. Tem 62 anos, ensino médio } \\
\text { incompleto, é aposentado, e vem participando dos grupos operativos há aproximadamente dois anos. }\end{array}$ \\
\hline E4 & $\begin{array}{r}\text { Mãe de uma criança que frequenta o CAPSi a mais de três anos. Tem 54 anos, ensino médio completo, } \\
\text { é do lar, e vem participando dos grupos há aproximadamente três anos. }\end{array}$ \\
\hline E5 & $\begin{array}{r}\text { Mãe de uma criança que frequenta o CAPSi a mais de dois anos. Tem 33 anos, ensino médio } \\
\text { completo, é do lar, e vem participando dos grupos há aproximadamente dois anos. }\end{array}$ \\
\hline E6 & $\begin{array}{r}\text { Avó de uma criança que frequenta o CAPSi a mais de dois anos. Tem 69 anos, ensino fundamental } \\
\text { incompleto, é doméstica, e vem participando dos grupos há aproximadamente dois anos. }\end{array}$ \\
\hline E7 & $\begin{array}{r}\text { Mãe de uma criança que frequenta o CAPSi a mais de dois anos. Tem 44 anos, ensino médio } \\
\text { completo, é autônoma, e vem participando dos grupos há aproximadamente dois anos. }\end{array}$ \\
\hline E8 & $\begin{array}{r}\text { Mãe de uma criança que frequenta o CAPSi a mais de três anos. Tem 40 anos, ensino fundamental } \\
\text { incompleto, é do lar, e vem participando dos grupos há aproximadamente um ano. }\end{array}$ \\
\hline
\end{tabular}

Após tratamento das falas dos sujeitos verificou-se mudanças em três áreas que serão descritas nas categorias abaixo:

\section{Mudanças na expressão de sentimentos}

Esta categoria corresponde a mudança na expressão dos sentimentos percebidas no familiar ao participar do grupo operativo. Uma das primeiras mudanças percebidas por E8 ao participar dos grupos operativos foi a expressão de seus sentimentos, em relação a muitas situações que a deixava preocupada.

Eu saía aliviada. Eu ficava muito preocupada com a medicação que ela tomava, das reações que tinha. Eu não conseguia falar com a médica, e isso me deixava preocupada. (E8) 
Os grupos operativos proporcionam aos familiares a oportunidade de expressarem os sentimentos vivenciados colaborando para o alívio das tensões geradas pelos conflitos que estes enfrentam com suas crianças e adolescentes em sofrimento mental. Evidências também apontam que os grupos operativos também funcionam como um espaço de esclarecimento, de escuta ${ }^{(11)}$ conforme explicita E4.

Para mim [o grupo operativo] foi uma terapia, desabafo também, foi uma maneira de expormos as dificuldades que passamos com nossos filhos, uma maneira de poder contar com o apoio de outras pessoas, eu pensava que me expondo, botando para fora, eu ia ter só críticas negativas, mas foi ao contrário, me deram bastante apoio, foi válido, eu contei com o apoio de muita gente, que pensava que não ia contar e isso para mim foi suficiente.(E4)

Algumas das vertentes necessárias para um grupo operativo atingir a tarefa proposta é a escuta. O não julgamento dos participantes e a compreensão "dos porquês" de seus sentimentos acabam propiciando uma atmosfera acolhedora percebida pela abertura que leva o sentir-se confortável na expressão dos seus sentimentos e na fluência do diálogo ${ }^{(13)}$. Desta mesma forma, a participante abaixo revela que sente-se aliviada ao perceber o grupo operativo como espaço para seus desabafos e ajuda mútua.

Quando você tinha um problema colocava ali, na hora desabafa, chora. Porque a gente prende o choro, mas naquele momento fica tão sensível e lá mostra vídeos que mostra história de vida, então ali a gente sente até uma sensibilidade e chora, é importante o desabafo, a gente ainda não se conhece, mas vai ajudando uma a outra.(E7)

Os grupos operativos podem tornar-se o próprio agente de cura, adequando-se as necessidades dos participantes, suprindo as lacunas que os integrantes apresentam, fazendo com que percebam a importância do grupo, ajudando-os, a conhecer todas as dificuldades do seu cotidiano, possibilitando oportunidade de mudanças na vida ${ }^{(2-13)}$.

Em vista desses aspectos, participar dos grupos operativos favoreceu mudanças nos sentimentos ${ }^{(21)}$ dos participantes conforme expõe E2.
[...] quando estamos na sala [onde ocorre os grupos operativos], entramos tristes e nos alegramos, para mim foi ótimo. (E2)

Constatou-se que os grupos operativos estimulam a expressão de sentimentos dos familiares e possibilitam mudanças nesses sentimentos. Percebe-se ainda que nutrem uma atmosfera de acolhimento que proporciona aos seus integrantes um espaço de escuta, de

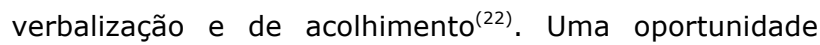
para o enfrentamento dos medos, das angústias, culpas e conflitos presentes no cotidiano dos cuidadores, permitindo-lhes o compartilhamento das inquietações através da integração entre participantes ${ }^{(21-24)}$.

Essas sensações expressas modificadas pode-se considerar, de acordo com a teoria de Pichon, uma adaptação ativa, no sentido de que o sujeito ao transformar-se, modifica o meio e ao modificar o meio, modifica-se a si mesmo. O compartilhamento de sensações entre os membros do grupo pode causar benefícios diretos às pessoas que deles participam, se estendendo para suas crianças. Desta forma o efeito de espiral permanente acontece, ou seja, quando um membro da família apresenta mudanças este efeito pode ser sentido e provocar mudanças em outro membro(11).

Pichon-Rivière aborda que o processo terapêutico tem como objetivo diminuir ansiedades psicóticas básicas, ou seja, diminuir um montante determinado de medos básicos, de perda e ataque, de forma que o ego do sujeito não precise recorrer à mecanismos de defesa, estereotipando-se, e impedindo-Ihe de uma adaptação ativa à realidade ${ }^{(11)}$.

Logo, estimular os familiares a compartilharem seus sentimentos, a partir da intervenção por meio de grupos operativos, constitui um aspecto da saúde mental que pode contribuir para uma melhor qualidade de vida desses familiares e para a melhor reinserção psicossocial dos que recebem os seus cuidados, estimulando mudanças a expressão dos sentimentos que muitos cuidadores sentem-se retraídos em confessá-los.

\section{Mudanças na percepção de si}

Após a participação nos grupos operativos, os familiares perceberam que ao modificarem a expressão dos seus sentimentos, mudanças em si também podem ser realizadas, entre elas estão às relacionadas ao seu próprio comportamento, ou seja, como os participantes dos grupos operativos perceberam seus pensamentos, emoções e atitudes após a participação nestes grupos. 
Depois dos grupos mudei para melhor, eu era estressada, mas agora mudei muito. (E2)

Os cuidadores entrevistados, afirmam que os grupos operativos contribuíram para mudanças no seu jeito de ser. A participação nos grupos operativos, segundo Pichon-Rivière, incentiva as pessoas a explorarem seus pensamentos, a fim de modificá-los a partir do momento que a realidade até então imposta e cristalizada, pode ser flexível e consequentemente mutável ao compartilhar seus conflitos. Além disso, os integrantes percebem que nem sempre seus comportamentos são condizentes com suas pretensões, e ao refletirem acerca dessa questão aprendem a ter um novo olhar de tudo que estar a sua volta, iniciando com mudanças subjetivas que se estende às relações de convivência no ambiente familiar ${ }^{(11,18,24)}$.

A literatura demonstra que o impacto do diagnóstico do sofrimento mental, a necessidade de adaptação à nova situação, o estigma social, a falta de apoio da família, a dependência dessas crianças e adolescentes, as implicações da cronicidade do quadro clínico podem produzir: sobrecarga, conflitos, sentimentos de incredulidade, perda do controle e medo, visto que o cuidador vivencia uma situação de desgaste, esquecendo-se de se cuidar. Porém o grupo operativo utiliza de artifícios a fim de enfatizar a importância do autocuidado, afirmando que a realidade até então imposta pode ser mutável, e os cuidadores ao perceberem essa quebra de estereótipos refletem a necessidade de modificar sua postura ${ }^{(1-11)}$. E2 e E7 ressaltam a importância de se cuidar.

[...] a maioria [dos integrantes do grupo operativo] sempre reclamava que a família não aceitava, ninguém ficava. Às vezes a gente deixa de cuidar da nossa saúde para cuidar da deles, porque não tem um apoio, as famílias não ficam. Você se doa para seus filhos e às vezes, se esquece de você para cuidar dele. Mas você tem que também se cuidar para cuidar dele. (E7)

[Após participação nos grupos operativos] [...] eu gosto de ajeitá-lo, mas também tenho que me arrumar, eu arrumo o meu cabelo, escovo, porque também a gente tem que se amar. Como é que vamos cuidar dele se não nos cuidarmos? Você tem que se cuidar para cuidar dele. (E2)

É notório que, para se estabelecer boa relação de convivência é preciso que os cuidadores também passem a se cuidar, pois no momento que estes buscam o valor do cuidado é que passam a compreender o sofrimento Rev. Eletr. Enf. [Internet]. 2014 jul/set;16(3):652-61. Disponivel em: http://dx.doi.org/10.5216/ree.v16i3.21777. - doi: 10.5216/ree.v16i3.21777. mental dos seus familiares, de modo que essa mudança possibilita uma aproximação entre os cuidadores e suas crianças e adolescentes ${ }^{(13-14)}$.

Nesses parâmetros, os grupos operativos ainda podem possibilitar outras mudanças nesses comportamentos dos cuidadores frente a suas crianças e adolescentes em sofrimento mental. A interação no grupo familiar se estrutura com base no interjogo de imagens internas. Quando em um grupo familiar emerge a doença mental, seus integrantes constroem uma imagem do sujeito que adoece conjugada com as imagens que eles possuem dos outros membros, de si mesmo e com o que acredita que os outros pensam deles. Então, se um dos familiares acredita que a pessoa que adoece é inválida, por exemplo, ele irá se desdobrar para suprir a necessidade daquele membro. Então, a tarefa corretora dos grupos operativos consiste na ratificação ou retificação dessas imagens em interjogo ${ }^{(11)}$.

A entrevistada 4 em seu depoimento reconhece que ao compartilhar suas dificuldades durante os grupos, ocorreram mudanças em si na forma como olhava para sua filha.

[Após os grupos operativos] Eu passei a vê-la não como uma menina que tinha problemas, mas como uma pessoa que precisava de ajuda. Hoje eu posso dizer a você que eu não só mudei assim em casa com ela, no ambiente familiar, como no relacionamento mãe e filha. (E4)

Pichon-Rivière aborda em seus estudos que a instabilidade no seio familiar corrobora para o mal prognóstico da criança ou adolescente em sofrimento mental. Uma abordagem eficaz são os grupos operativos que possibilitam uma abertura para os cuidadores se expressarem quanto as suas condutas frente ao sofrimento mental de seus parentes, na tarefa que o grupo pode vir a executar ${ }^{(11,13)}$, assim como E1 evidencia.

[...] eu não era de conversar com as pessoas, só ouvia, mas quando você passa a participar de um grupo operativo, com várias pessoas em disposição para que todos possam falar, você começa ouvir e sente vontade de falar e fala, aconselha as pessoas que gosta, e vocês [estudantes e professores] passam coisas boas pra gente [...] quanto mais você faz, mais dá vontade de fazer e não desistir, ainda mais quando você tem apoio. (E1) 
$\mathrm{O}$ ato de escutar e dialogar estimula aos participantes a modificarem seus comportamentos. Evidências apontam que ao compreender a natureza do sofrimento, é possível se ajudar e ajudar aos outros. Corroborando inclusive na mudança de comportamento com as outras pessoas, principalmente aquelas que recebem os cuidados, como as crianças e adolescentes em sofrimento mental ${ }^{(26)}$.

Para tanto, a participação nos grupos operativos favorece a troca de experiências, de enfrentamento dos problemas, gerando apoio mútuo e solidariedade, além de promover a criação de laços de amizade e confiança, o que favorece positivamente o resgate da auto-estima, uma das premissas para mudanças no comportamento que possibilitam melhor convívio familiar, com menores conflitos. Sendo assim, ao adquirir mudanças na percepção de si, os cuidadores percebem melhoras no convívio com seu familiar em sofrimento, mas que estes avanços também dependem muito do manejo adquirido ao lidar com as dificuldades apresentadas pelo adoecimento mental.

\section{Aprendizagem de técnicas para lidar com o sofrimento mental}

Outra categoria encontrada no estudo foi à mudança na forma de cuidar, após os cuidadores após participarem dos grupos operativos e relatarem o aprendizado de técnicas para lidar melhor com seus filhos e netos em sofrimento mental.

[...] ele era muito travesso, vivia correndo (...) [Hoje] ele chega senta no seu cantinho e sabe respeitar. Eu digo: fique lá no cantinho para os meninos não tá arengando com você. (E6)

O cuidado no âmbito familiar pode apresentar uma série de significados, evidenciando que a forma de manejo para com suas crianças influencia na formação psicoemocional das mesmas, e os cuidadores podem portar-se de diversas formas, entre elas: autoritários, agressivos, superprotetores, compreensivos, muito permissivos ou inseguros, neste último é decorrente de estados de ansiedade por não saber lidar, muitas vezes, com comportamentos que as crianças e adolescentes apresentam $^{(11,15-21)}$.

Vale ressaltar que não há fórmula específica para criar, educar os filhos, netos, sobrinhos, há sim técnicas de manejo que contribuem para um melhor convívio no meio familiar, e essas técnicas possibilitam a resolução de conflitos com maior adequação, entre as técnicas Rev. Eletr. Enf. [Internet]. 2014 jul/set;16(3):652-61. Disponivel em: http:// encontra-se a imposição de limites. No entanto, muitos cuidadores sentem-se angustiados, frente ao comportamento que suas crianças e adolescentes apresentam, levando-os a insegurança de como saber abordá-los quanto à imposição de limites $^{(3-15)}$.

Com frequência, o termo limites é empregado de forma queixosa, sendo associado à obediência, ao respeito, à disciplina, retidão, moral e cidadania. o mesmo autor ainda afirma que o vocábulo limite trata daquilo que é permitido ou proibido, ou seja, a colocação de limites, neste sentido, faz parte do processo educativo e civilizador, pois a ausência destes poderia gerar uma crise de valores e um retorno a um estado de selvageria $^{(3)}$. E2 evidencia como aprendeu através dos grupos a melhor forma de impor limites ao seu filho:

[...] ele era muito agressivo comigo, depois que participei desse grupo operativo, botei limite nele. (E2)

A colocação de limites não significa simplesmente a imposição de uma série de comportamentos, mas relaciona-se com o ato de ajudar a criança a construirse, ensinando-Ihe o respeito por si mesma e pelos outros que fazem parte de seu convívio. Através dos grupos operativos os pais ao avaliarem suas condutas, podem perceber um novo olhar frente à realidade que enfrentam, sentindo muitas vezes a necessidade de mudar sua postura de como educar seus filhos e impor limites aos mesmos ${ }^{(11)}$. Assim como a E2 evidenciou.

[...] eu melhorei com vocês [estudantes e professores], me alertando como não brigar com ele em casa, ter limite, [...] depois que eu participei desse grupo, botei limite nele, porque a mãe é uma flor, a pessoa não pode está falando alto com a mãe, tem que respeitar. (E2)

Para que essas habilidades possam ser desenvolvidas faz-se necessário uma conduta por parte dos adultos, no caso dos pais e/ou cuidadores, em manter um equilíbrio entre exigência e flexibilidade, isto é, ensinar a importância de cumprir regras quando necessário e ceder quando for preciso(21).

Para tanto é indispensável que os cuidadores aprendam técnicas de abordagens relacionais compreendendo que impor limites não é falta de afeto ou punição, mas sim uma forma de educar, também é preciso saber compreender, escutar e ter diálogo, a fim de que estes ao tornarem-se adultos possam desenvolver relacionamentos mais resistentes diante das frustrações que o meio social em que vivem podem dx.doi.org/10.5216/ree.v16i3.21777. - doi: 10.5216/ree.v16i3.21777. 


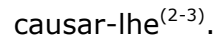

Esta aprendizagem de técnicas, para Pichon está relacionada ao autoconhecimento que a família passa a ter sobre seu funcionamento. Para ele, a família começa a obter uma adaptação ativa da realidade quando adquire insight, ou seja, quando se torna consciente da estrutura e da dinâmica familiar reconhecendo suas dificuldades e cada um de seus papéis. É preciso reconhecer que a situação conflitiva que a doença pode gerar, não é de fato originária pelo membro da família adoecido. $\mathrm{Na}$ verdade, este membro opera como depositário das tensões da família passando a ser o denunciante da situação conflitiva. A criança ou adolescente adoecido muitas vezes passa a ser o portavoz dos conflitos já existentes na família(11).

Deste modo a partir do autoconhecimento, a família passa a reconhecer seus papéis e limites, por exemplo, de pai, mãe e filho, e com isso reconhecer que as funções de cada papel podem estar distorcidas o que tem provocado mais conflitos com o aumento do nível de ansiedade naquela família. Neste caso o terapeuta realiza o manejo adequado chamado timing do esclarecimento, colaborando com a tarefa corretora de reconstruir as redes de comunicação ${ }^{(11)}$. Manejo utilizado em diversos momentos durante o grupo, para levar os familiares a reconhecer suas fragilidades sem que saíssem do ambiente do grupo angustiados.

Vale ressaltar que dos reconhecimentos e das aprendizagens, a permissividade dos pais em relação aos seus filhos, foi um conteúdo bastante trabalhado. A permissividade em tempo integral as crianças e adolescentes os predispõe a tornarem-se sem limites e em muitos casos, agressivos ${ }^{(3-13)}$. E7 afirma como as técnicas adequadas de manejo melhoram a relação de convivência.

[...] quando a gente para, ver o que recebeu desse grupo terapêutico, começa a mudar, tenta ajudar também eles [...] E apliquei em casa, passei a observar mais as coisas que acontece com ele, conversar, chamar. o diálogo é muito importante, comecei também a mostrar para ele que não é assim que se deve fazer, mas também ter paciência, tentar ajuda-lo, falar uma coisa, duas, três vezes, ter mesmo a paciência de falar. A gente tem que falar várias vezes com ele, até se situar $e$ voltar para o nosso mundo. (E7)

Essas técnicas de manejo adquiridas pelos entrevistados foram temáticas trabalhadas durante diversos grupos operativos que buscaram estimular Rev. Eletr. Enf. [Internet]. 2014 jul/set;16(3):652-61. Disponível em: http://dx.doi.org/10.5216/ree.v16i3.21777. - doi: 10.5216/ree.v16i3.21777. cuidadores a expressarem as formas que lidam com suas crianças e adolescentes. Segundo Pichon-Rivière, a troca de experiências entre os pais facilitam a realização da tarefa, pois estes atingem uma horizontalidade grupal, ou seja, tornam-se coesos, através da ajuda mútua passam a observar de que forma a realidade que lhe é imposta pode ser modificada, principalmente no que concerne o manejo adequado para com suas crianças e adolescentes em sofrimento mental ${ }^{(11,15)}$.

Assim, a educação dos filhos, embora seja tarefa complexa, deve ser baseada num ambiente familiar de: paz, carinho, compreensão, escuta e diálogo. O direito e dever dos pais de educar seus filhos implica, necessariamente, meio para impor limites, meios e modos de correção, essencialmente educativa, à medida que, imputam valores imprescindíveis para o desenvolvimento dessas crianças e adolescentes, o que se constitui, sem dúvida, em um verdadeiro ato de amor $^{(3)}$.

Vale ressaltar, que ao aprender novas técnicas de manejo para lidar com seus filhos, netos, as relações de convivência tendem a modificar-se à medida que os cuidadores (pais, avôs, tios) percebem que uma nova postura associada ao ato de escutar e dialogar podem contribuir para relações menos conflituosas ${ }^{(21)}$.

Sendo assim afirma-se que os grupos operativos ao estimular mudanças na expressão de sentimentos, contribuem para mudanças em seu comportamento e colaboram na aprendizagem de técnicas de manejo para lidar com o sofrimento mental. Além disso, os profissionais de enfermagem devem estar atentos as lacunas que os integrantes apresentam, de modo que os grupos terapêuticos sejam flexíveis a fim de que os familiares ao atingirem a interação grupal possam modificar a realidade que Ihes foram imposta, quebrando estereótipos, obtendo assim uma nova leitura da realidade, e consequentemente colaborando para o sucesso terapêutico de suas crianças e adolescentes em sofrimento mental.

\section{CONCLUSÃO}

A pesquisa constatou que os efeitos benéficos dos grupos operativos de modalidade terapêutica proporcionam aos familiares e, consequentemente, as crianças e adolescentes em sofrimento mental, mudanças positivas em suas relações interpessoais.

Muitas necessidades foram apontadas durante os grupos operativos, que ao serem trabalhadas levaram a mudanças, entre elas a expressão de sentimentos, o aprendizado de técnicas de manejos, a redução dos 
conflitos e a melhora nas relações de convivência. Para tanto, mudanças comportamentais ocorreram a partir do momento que os familiares perceberam que suas atitudes faziam mal a si e àqueles que estavam sob seus cuidados.

Quanto a realização dos grupos foi possível perceber que a utilização da teoria de grupo pichoniana de "forma adaptada", tornou-se indispensável para a mobilização de estruturas estereotipadas na estrutura familiar dos sujeitos da pesquisa. É possível facilitar grupos operativos baseados na teoria pichoniana, mesmo sem que estes grupos se configurem como psicoterapêuticos. Para isto é necessário o aprofundamento da teoria a fim de conhecer os conceitos e métodos que favorecem a mudança de pensamentos e comportamentos.

No entanto ressalva-se que esta não é a única teoria, e que outras podem ser acessadas com o objetivo de provocar, de fato, mudanças na estrutura psíquica. Uma atividade grupal não deve ser realizada de forma empírica, sem a mínima compreensão de quão complexa é a facilitação de grupos operativos. Os profissionais que se consideram habilitados para coordenar este tipo de atividade, e em especial os enfermeiros, devem estar preparados para entender como emerge o processo grupal e qual a técnica adequada para mediação de conflitos que culminem em mudanças.

O estímulo a utilização de teorias grupais deve acontecer desde a graduação, e deve ser reforçada com a educação permanente no cotidiano dos serviços de saúde, o conteúdo a ser estudado é inesgotável, nunca se sabe suficientemente como conduzir grupos que sejam acolhedores e com maiores chances de serem operativos e provedores de uma transformação positiva na qualidade da convivência. Sendo assim, investimentos na formação passam a ser de extrema necessidade para a qualificação de profissionais capazes de suscitar transformações na vida das pessoas em que cuidam.

\section{REFERÊNCIAS}

1. Borba LO, Scwartz E, Kantorski LP. A sobrecarga da família que convive com a realidade do transtorno mental. Acta paul. enferm. [Internet]. 2008 [acesso em: 30 set 2014];21(4):58894. Disponível em: http://dx.doi.org/10.1590/S010321002008000400009 .

2. Mangueira SO, Lopes MVO. Família disfuncional no contexto do alcoolismo: análise de conceito. Rev Bras Enferm

[Internet]. 2014 [acesso em: 30 set 2014];67(1):149-54. Disponível em: http://dx.doi.org/10.5935/0034-7167.20140020. 3. Moretto CC. O grupo como estratégia de intervenção em saúde mental da infância e adolescência. Mental [Internet]. 2013 [acesso em: 30 set 2014];X;(19):221-33. Disponível em: http://pepsic.bvsalud.org/scielo.php?script=sci_arttext\&pid=S16 79-44272013000100005\&lng=es\&nrm=is\&tIng=pt.

4. Silva MBC, Sadigursky D. Representações sociais sobre o cuidar do doente mental no domicílio. Rev Bras Enferm [Internet]. 2008 [acesso em: 30 set 2014]; 61(4):428-34. Disponível em: http://dx.doi.org/10.1590/S003471672008000400005 .

5. Nascimento YCML, Rosa LS, Souza JC, Véras YAR, Brêda MZ, Trindade RFC. Perfil de crianças e adolescentes acompanhados por um centro de atenção psicossocial infanto-juvenil. Rev enferm UFPE on line [Internet]. 2014 [acesso em: 30 set 2014];8(5):1261-72. Disponível em:

http://www.revista.ufpe.br/revistaenfermagem/index.php/revista /article/viewArticle/5528.

6. Portaria no 3088, de 23 de dezembro de 2011 (BR) [Internet]. Institui a Rede de Atenção Psicossocial para pessoas com sofrimento ou transtorno mental e com necessidades decorrentes do uso de crack, álcool e outras drogas, no âmbito do Sistema Único de Saúde (SUS). Diário Oficial da União. 21 mai. 2013 [acesso em: 30 set 2014]. Disponível em: http://bvsms.saude.gov.br/bvs/saudelegis/gm/2011/prt3088_23 12_2011_rep.html.

7. Wunsch CG, Lucchese R. Os instrumentos terapêuticos utilizados pelas equipes dos Centros de Atenção Psicossocial do Mato Grosso. Saúde em Debate. 2010;34(86):576-86.

8. Munari DB, Lucchese R, Medeiros M. Reflexões sobre o uso de atividades grupais na atenção a portadores de doenças crônicas. Ciênc. cuid. saúde. [Internet]. 2009 [acesso em: 30 set 2014];8 Supl:148-54. Disponível em: http://dx.doi.org/10.4025/cienccuidsaude.v8i0.9742. 9. Valdez CR, Padilla B, Moore SM, Magaña S. Feasibility, acceptability, and preliminary outcomes of the Fortalezas Familiares intervention for latino families facing maternal depression. Fam Process [Internet]. 2013 [acesso em: 30 set 2014];52(3):394-410. Disponível em: http://dx.doi.org/10.1111/famp.12033.

10. Finkel LA. O lugar da mãe na psicoterapia da criança - uma experiência de atendimento psicológico na saúde pública. Psicol. cienc. prof. [Internet]. 2009[acesso em: 30 set

2014];29(1):190-203. Disponível em:

http://dx.doi.org/10.1590/S1414-98932009000100016.

11. Pichon-Rivière E. O processo grupal. $8^{a}$ ed. São Paulo: WMF Martins Fontes, 2009.

12. Bourguignon LN, Guimarães EDS, Siqueira MMD. A atuação do enfermeiro nos grupos terapêuticos dos CAPS AD do Estado do Espírito Santo. Cogitare enferm. [Internet]. 2010 [acesso em: 30 set 2014$] ; 15(3): 467-73$. Disponível em: http://dx.doi.org/10.5380/ce.v15i3.18889.

13. Pereira TTSO. Pichon-Rivière, a dialética e os grupos operativos: implicações para pesquisa e intervenção. Rev. SPAGESP [Internet]. 2013 [acesso em: 30 set 2014];14(1):21-9. Disponível em:

http://pepsic.bvsalud.org/scielo.php?script=sci_arttext\&pid=S16 77-29702013000100004.

14. Afonso MLM, Vieira-silva M, Abade FL. O processo grupal e a educação de jovens e adultos. Psicol Estud [Internet]. 2009 [acesso em: 30 set 2014];14(4):707-15. Disponível em: http://dx.doi.org/10.1590/S1413-73722009000400011.

15. Bastos ABBI. A técnica de grupos-operativos à luz de PichonRivière e Henri Wallon. Psicol. inf [Internet]. 2010 [acesso em: 30 set 2014$] ; 14(14): 160-9$. Disponível em: https://www.metodista.br/revistas/revistasims/index.php/PINFOR/article/view/2348.

16. Almeida SP, Soares SM. Aprendizagem em grupo operativo de diabetes: uma abordagem etnográfica. Cien Saude Colet [Internet]. 2010 [acesso em: 30 set 2014];15 Supl 1:1123-32. Disponível em: http://dx.doi.org/10.1590/S1413-

81232010000700020.

17. Moretto CC, Terzis A. Experiências de uma equipe interdisciplinas de saúde mental. Rev. SPAGESP [Internet]. 2012 [acesso em: 30 set 2014];13(2):68-76. Disponível em: 
http://pepsic.bvsalud.org/scielo.php?script=sci_arttext\&pid=S16 77-29702012000200008.

18. Cardoso ASF, Dall'Agnol CM. Group Process: reflections of a nursing team. Rev Esc Enferm USP [Internet]. 2011 [acesso em: 30 set 2014];45(6):1412-8. Disponível em:

http://dx.doi.org/10.1590/S0080-62342011000600019.

19. Minayo, MCS. O desafio do conhecimento: pesquisa qualitativa em saúde. $11^{\circ}$ ed. São Paulo: Hucitec; 2010.

20. Bardin L. Análise de Conteúdo. Lisboa: Edições 70; 2009.

21. Navarini V, Hirdes A. A família do portador de transtorno

mental: identificando recursos adaptativos. Texto Contexto

Enferm [Internet]. 2008 [acesso em: 30 set 2014];17(4):680-8.

Disponivel em: http://dx.doi.org/10.1590/S0104-

07072008000400008.

22. Benevides $\mathrm{DS}_{L}$ Pinto $\mathrm{AGA}$, Cavalcante $\mathrm{CM}_{\perp}$ Jorge

MSB. Cuidado em saúde mental por meio de grupos terapêuticos de um hospital-dia: perspectivas dos trabalhadores de saúde. Interface (Botucatu) [Internet]. 2010 [acesso em: 30 set 2014];14(32):127-38. Disponível em:

http://dx.doi.org/10.1590/S1414-32832010000100011.

23. Kantorski LP, Coimbra VCC, Demarco DA, Eslabão AD, Nunes

CK, Guedes AC. A importância das atividades de suporte

terapêutico para o cuidado em um Centro de Atenção. Rev.

enferm. saúde [Internet]. 2011 [acesso em: 30 set

2014];1(1):4-13. Disponível em:

http://periodicos.ufpel.edu.br/ojs2/index.php/enfermagem/articl e/view/3401.

24. Marini AM, Martins MRI, Souza AV, Marques Filho AB, Pontes HER. Sobrecarga de cuidadores na psiquiatria infantil. Rev

Neurocienc [Internet]. 2010 [acesso em: 30 set

2014];18(3):300-6. Disponível em:

http://www.revistaneurociencias.com.br/edicoes/2010/RN1803/4 77\%20original.pdf.

Artigo recebido em 29/10/2012.

Aprovado para publicação em 07/02/2014.

Artigo publicado em 30/09/2014. 